\title{
DEVELOPING A PROJECT PORTFOLIO SELECTION MODEL FOR CONTRACTOR FIRMS CONSIDERING THE RISK FACTOR
}

\author{
Hamidreza Abbasianjahromi ${ }^{1}$, Hossein Rajaie ${ }^{2}$ \\ Department of Construction Engineering and Management, Amirkabir University of Technology, \\ Hafez Ave, 15914 Tehran, Iran \\ E-mails: ${ }^{1}$ abasian.hamid@gmail.com (corresponding author); ${ }^{2}$ rajaieh@aut.ac.ir \\ Received 09 Feb. 2011; accepted 02 Jun. 2011
}

\begin{abstract}
Regarding to the high importance of project selection in the project life cycle, solving bid/no-bid problems, especially in the construction industry, is a subject of most recent research. Portfolio selection has been the most interesting area in the last two decades in management research but there is poor investigation in the construction industry. Taking into account the risk, which is inherent in the construction industry and especially in the project selection phase is inevitable. This paper intends to propose a model for project selection and developing two main concepts including company portfolio and risk. The main innovation of this paper is presenting a new framework, which attempts to optimize project selection based on the endurable risk level of a company with regard to the existing portfolio. Considering the user-friendly characteristic of the model, this paper has applied the fuzzy multi criteria decision-making approaches. Finally, the model is implemented in a real case study.
\end{abstract}

Keywords: risk, project selection, portfolio, MCDM problems, Fuzzy set theory.

\section{Introduction}

Modern societies need to define numerous construction projects for enhancing the convenience of their inhabitants, and as a result, the selection of project portfolio is one of the most effective and permanent activities in each organization. Previous researchers considered project portfolio selection from various viewpoints, including employer, contractor and consultant. Each part has its special concerns but for contractors, project portfolio selection is a crucial phase. Project selection in deciding whether or not to bid for a job is a vital and recurring strategic decision for construction firms as many contractors obtain a large portion of their jobs through competitive bidding (Oo et al. 2008). In the other point of view, many factors such as uniqueness of project conditions, cooperation and interdependency of the construction industry with others, innovation in the execution phase, and the inherent complexity in this industry causes the ability of prediction in this area to reduce remarkably. In vague and challenging circumstances, the probability of occurring incidents arises; therefore, making decisions in the construction industry has a high risk. Some researchers have argued that contractors are poor in responding to the risk and they are not capable enough for handling risks (Ahmed et al. 2002; Baloi, Price 2003). There exist many reasons for developing research in project portfolio selection considering risk factors, especially for contractor companies. Initially, due to limited resources of contractor firms, appropriate selection of projects is one of the most important decisions in the resource allocation process. Secondly, one of the most important steps in strategy implementation is project (or program or activity) selection, so project selection is a tool for reaching the company goals. The other reason is the complex nature of the construction industry. Due to the dynamic and unique features of each project and various interfering risk criteria in this phase, selection is the complicated activity. Mullich (1998) showed that managing risks and obtaining high benefit in the construction projects is probable by using a portfolio theory. The forth reason is the survival of the contractor companies. Perpetuity of each company is directly related to performing various projects and obtaining outcome. Selection of a proper project can guarantee progress of a company. Finally, reducing the company risk level with the selection of a low risk project in most previous models offered by researchers is the main product of inattention to the condition of a company. Presenting a model or framework for realist modeling of risk in the project selection is essential.

Regarding the two major taxonomies in previous works on project portfolio selection, the first category discusses the application of the project portfolio selection concept in various fields and the second one speaks about different tools for solving project portfolio selection. This paper is clearly located in the second group. The authors think that the construction industry is one of the high risky industries in the world and if contractors are capable of making a right decision in a risky circumstance, they can obtain a considerable benefit for their companies. Project portfolio selection is the first decision, which influences various aspects and is very vital. This paper intends to propose a model for project portfolio selection considering the risk in contractor firms. 
Considering this implication of research on project portfolio selection, the current research attempts to achieve the following objectives:

1. To alter the points of view about project or project portfolio selection considering risks which are predominant in most previous works;

2. To propose a framework which is applicable not only for project portfolio selection but also for evaluation of project risks.

The structure of the current paper is planned to describe the essence of the work and to clarify the methodology and main interest areas in the introduction section. A brief literature review has been presented in the literature survey. The developed step-by-step model is presented in section 3, and in section 4 the model has been applied in a case study to demonstrate the model application and finally in the conclusion section a brief result of the paper will be presented.

\section{Literature review}

Because this paper has combined several topics, this section reviews previous works in three categories including: a) project selection methodologies; b) project selection considering risk; and c) the application of portfolio in the construction industry.

a) Project selection methodologies. Schmidt and Freeland (1992) explained that the use of numerical and step-by-step methodologies for evaluating projects, were deployed after World War II. Archer and Ghasemzadeh (1998) proposed a project portfolio selection framework and a decision support system (DSS) named Project Analysis and Selection System. Molenaar and Songer (1998) suggested that such multi-criteria (or multiattribute) analyses are suitable for the project selection. Wong et al. (2000) applied First Stochastic Dominance (FSD) as a new tool for multi-attribute decision making in project selection. Lin and Chen (2004) developed a model based on fuzzy set theory. In their approach, clients evaluate projects with some proposed criteria by using a set of linguistic terms. Owing to the complexity of a construction project, Cheng and Heng (2005) developed a model based on the analytic network process (ANP). Han et al. (2005) proposed a methodology for selection of international projects based on the risk factor. Hao and Xie (2006) presented a model based on fuzzy TOPSIS for bid/no-bid decision-making. Mahmoodzadeh et al. (2007) developed a model based on AHP and fuzzy TOPSIS for evaluation of projects in the bidding. Carlsson et al. (2007) and Wang and Hwang (2007) had fuzzy contribution. They separately utilized a model based on fuzzy set theory for their R\&D project selection models. Huang et al. (2008) utilized fuzzy AHP for selection of R\&D projects. Tan et al. (2010) suggested a model based on combining multi attribute decision-making and fuzzy set theory. Their model used the fuzzy TOPSIS approach in the construction project selection. Ravanshadnia et al. (2010) investigates three policies in project selection. They considered to the concentration, diversification and neutral policies in bidding and they demonst- rated results are directly related to the strategy, which decision makers choose. They used fuzzy multi-attribute decision making in their research.

According to the literature survey on project selection, models can be categorized into two main groups inclusive of stochastic approaches and fuzzy approaches. In the recent years, most models, which are conducted in this field have considered fuzzy approaches with a combination of multi criteria decision making (MCDM) models. It seems that fuzzy MCDM methods are more useful and applicable than others are for the present conditions of the construction industry for project selection.

b) Project selection considering risk. Moselhi and Deb (1993) presented a simple methodology for the selection of a project under risk. The method considers multi-objective decision criteria and takes into account the uncertainties associated with each individual objective. Tah et al. (1993) developed a model for evaluating contractors' risks in the tendering phase. They used the principles of fuzzy set theory for covering the construction risks. Baker et al. (1998) surveyed risk analysis techniques employed by the companies. They concluded that personal and corporate experience and engineering judgment are the most successful qualitative techniques; scenario analysis, EMV, ENPV, and break-even analysis being the principal quantitative techniques. Ye and Tiong (2000) developed the net-present-value-at-risk (NPV-atrisk) method to decide to invest in privately financed infrastructure projects or not. Carr and Tah (2001) suggested a model based on a hierarchical risk breakdown structure and fuzzy approximation to identify and quantify the relationships between risk sources and consequences. Ziara et al. (2002) developed a risk-based analytical hierarchy process for infrastructure project prioritization. Because of existing uncertainties in the construction industry, Liu and Ling (2005) proposed a fuzzy logic based artificial neural network model for bidding price. Zeng et al. (2007) used a modified analytical hierarchy process to prioritize diverse risk factors. They applied fuzzy reasoning techniques to handle the uncertainties and subjectivities arising in the construction process.

Project selection models considering risk can be sorted into two main categories. Some researchers initially proposed a model based on financial risks. In these types of models, the consequences of risks were evaluated based on cost overrun; consequently, these models have a capability of predicting markup coefficient in biding. Stochastic approaches are the most important tools in this field. In the second group, researchers just evaluate and rank projects based on their risks. In these models, MCDM methods, fuzzy set theory and the expert system are the most important tools. Because the aim of this paper is to evaluate project risks, the method of this paper is placed in the second group.

c) The application of portfolio in the construction industry. The first attempts for applying the portfolio theory in construction were done by Vergara. In the first step of his models, he analyzed proposed projects one by one. In the next step, the condition of the existing organi- 
zation portfolio was evaluated and finally the appropriate projects regarding the status of the proposed projects and existing portfolio for improving the characteristics of the organization portfolio were selected (Vergara 1977). Kangari and Boyer (1981) presented a model based on portfolio theory for project selection, but in 1988 Kangari and Riggs confessed that the model had some serious problems and they said that calculating the covariance of projects is not as simple as in marketing. Han (1999) used the portfolio theory with financial analysis for selection and evaluation of international projects. Veshosky (1994) spoke about the portfolio approach and the diversification strategy for improving the position of firms in the market and for starting in the new business. Based on his investigation in American firms, the portfolio theory can satisfy this object. Olsson (2008) comprised the single project management and project portfolio management in his study. Because of project portfolio advantages, he proposed a methodology based on the portfolio theory for managing risks in a multi-project environment.

While project selection considering the existing project portfolio of a company is the realistic approach, the number of investigations conducted in this field is very few. Models developed in the construction project selection just focus on evaluating a project and they do not consider the interaction of selection in other fields such as resource allocation. In addition, the developing concept of portfolio theory in the construction industry is very poor and few researchers who develop a model in this area have proposed complicated and inapplicable models. This paper intends to present a simple and applicable model in evaluation of candidate projects to add to the existing portfolio.

\section{Hybrid fuzzy MCDM model for project portfolio selection}

The main concern of the authors is to propose a systematic model for reducing the inherent vagueness of the construction industry and the complexity of project selection problems especially in the domain of project portfolio selection considering risk. The proposed model has been constituted from three main steps and several sub-steps in each category. This model identifies the new terminology entitled "the risk endurable level of company" (RELC). Introducing RELC is necessary to cover the lack of previous models in inattention to the present condition of the company for determining the best strategy in selection of project or project portfolio. By using this item, decision makers can decide with minimum mistakes. The model weights and evaluates criteria with the use of MCDM methods. Regarding the interdependency of the construction industry to the expert judgments, the fuzzy set theory will be aided in this phase. Finally, goal programming, which is one of the MCDM methods for optimizing selection, will be used.

\subsection{Establishing risk based bid evaluation criteria}

There exist several risks in the construction industry, but working with all of them is not possible and applicable.
Generally, it is not a realistic approach to develop a set of definite risks. In each country, there exist different parameters generated to risk in construction projects and they directly depend on the condition of countries or projects. In this section, each company should prepare a set of risks, which are derived from academic research, experts' experience and previous historical records.

After developing a set of risks, weighting is the next step, which is vital in determining the importance of risks. There exist numerous tools for satisfying this purpose such as MCDM methods, numerical methods, expert judgment etc. One of the simple methods suggested by authors is that experts express their opinion about probability and consequences of each risk by a number between 1 and 9 ( 1 is the lowest limit). Finally, there would exist a number resulting from a multiplication between the probability and consequence number of each criterion based on each expert judgment. For the next step, a mean of their judgments for each risk is calculated. In order to have a final normalized weight, a normalization process would be done based on the following equation:

$$
w_{i}=\frac{x_{i}}{\sum_{i=1}^{n} x_{i}},
$$

where $x_{i}$ is the mean weight of the $i^{\text {th }}$ criterion based on expert judgments and $w_{i}$ is a normalized weight of the $i^{\text {th }}$ criterion that would be between 0 and 1 .

\subsection{Determining the risk endurable level of the company (RELC)}

There exist several parameters, which can influence the evaluation of the RELC, for instance:

- Capacity of company in execution of different projects;

- The number of existing projects;

- Duration of existing projects;

- The level of existing company project portfolio risk;

- Financial capability of company;

- Human resource and equipment of company.

Because of the numerousness and variety of these parameters, MCDM approaches are the best solution for handling this problem. Contrary to other industries, in the construction industry, evaluation of criteria is done based on expert's judgments. Fuzzy set theory is one of the tools, which can handle linguistic terms. It seems that the combination of the two proposed approaches can be useful for determining the RELC.

\subsubsection{Developing the FSAW method}

There are several methods in the fuzzy MCDM solutions, which are useful for a special application. The SAW method is probably the best-known and most widely used MCDM method (Kahraman 2008). SAW can be transferred into fuzzy SAW by inserting the expert's judg- 
ments and working with linguistic terms. In this approach, each project can obtain a score based on Eq. (2):

$$
U=\sum_{i=1}^{n} w_{i} r_{i j},
$$

where $w_{i}$ is the weight of criterion $i^{\text {th }}$ and $r_{i j}$ is the rate of alternative $j^{\text {th }}$ which is the endurable risk level of the company with respect to criterion $i^{\text {th }}$. In the FSAW, these parameters are expressed based on fuzzy numbers. When:

$$
w_{j}=\left\{\left(y_{j}, \mu_{w j}\left(y_{j}\right)\right)\right\},
$$

and

$$
r_{i j}=\left\{\left(x_{i j}, \mu_{r_{i j}}\left(x_{i j}\right)\right)\right\},
$$

where $y_{j}$ and $x_{i j}$ take their numbers on the real line $\mathrm{R}$ and $\mu_{w j}\left(y_{j}\right)$ and $\mu_{r_{i j}}\left(x_{i j}\right)$ take values in $[0,1]$. The utility of alternative $A_{i}, u_{i}=\left\{\left(u_{i}, \mu_{u_{i}}\left(u_{i}\right)\right)\right\}$ can be calculated as follows.

The variable $u_{i}$ takes its value on the real line $\mathrm{R}$ and can be obtained using:

$$
u_{i}=\sum_{j=1}^{n} y_{j} x_{i j} / \sum_{j=1}^{n} y_{j}
$$

the membership function $\mu_{u_{i}}\left(u_{i}\right)$ can be calculated using:

$$
\mu_{u_{i}}\left(u_{i}\right)=\sup _{\vee}\left\{\left[\wedge_{j=1}^{n} \mu_{w_{j}}\left(y_{j}\right)\right] \wedge\left[\wedge_{j=1}^{n} \mu_{r_{i j}}\left(x_{r_{j}}\right)\right]\right\},
$$

where $\vee=\left(y_{1}, \ldots, y_{n}, x_{i 1}, \ldots, x_{i n}\right)$.

The membership function $\mu_{u_{i}}\left(u_{i}\right)$ is not directly obtainable when $\mu_{w_{j}}\left(y_{j}\right)$ and $\mu_{r_{i j}}\left(x_{i j}\right)$ are piecewise continuously differentiable functions. To resolve this difficulty and preserve the simplicity of the SAW method, several approaches have been proposed (Baas, Kwakernaak 1977; Dubois, Prade 1982; Cheng, McInnis 1980; Bonissone 1982; Vanegas, Labib 2001; Bector et al. 2002). In this paper Vanegas and Labib's approach is used.

Their approach is based on operating fuzzy numbers to derive the weight of each alternative. Operating on fuzzy numbers is done according to the $\alpha$-cut concept. The desirability of alternatives can be represented as $D_{1}$, $D_{2}, \ldots, D_{n}$ and the weight of attributes is represented as $W_{1}, W_{2}, \ldots, W_{n}$ therefore:

$$
D_{\alpha}=\left[D_{\alpha a}, D_{\alpha b}\right]
$$

where:

$$
D_{\alpha a}=\min \left(\frac{\sum_{i=1}^{n} D_{i \alpha a} \times W_{i}}{\sum_{i=1}^{n} W_{i}}\right),
$$

and

$$
D_{\alpha b}=\max \left(\frac{\sum_{i=1}^{n} D_{i \alpha b} \times W_{i}}{\sum_{i=1}^{n} W_{i}}\right),
$$

where: $W_{i} \in\left[W_{i \alpha a}, W_{i \alpha b}\right]$ for all $i \in\{1,2,3, \ldots, n\}$ and $\alpha \in(0,1] ; D_{a a}$ and $D_{a b}$ represent the lower and upper limits of the $\alpha$-cut $D_{i \alpha}$, respectively; and $D_{i \alpha a}$ and $D_{i \alpha b}$ represent the lower and upper limits of the $\alpha$-cut, respectively; and $W_{i a a}$ and $W_{i \alpha b}$ represent the lower and upper limits of the $\alpha$-cut $W_{i \alpha}$, respectively. The "min" and "max" operators take the minimum and maximum values, respectively, which can be calculated through a combination of the $W_{i}$ in all the possible ways. The set of $W_{i}$ that is used in the numerator has to be the same as the one in the denominator.

\subsubsection{Defining linguistic terms and fuzzy numbers}

A linguistic variable is a variable, which is expressed in linguistic terms. The concept of a linguistic variable is very useful to describe a situation that is too complex or has vagueness. This paper uses linguistic variable for getting the opinion of experts in various steps of proposed model.

Zadeh (1965) cited that these linguistic variables can be expressed in fuzzy number form. A fuzzy number is a fuzzy subset of the universe of discourse $X$ that is both convex and normal. There are several fuzzy numbers but in the construction industry, triangular and trapezoidal fuzzy numbers are the most used (An et al. 2005). In this paper, triangular fuzzy numbers are used. The triangular fuzzy numbers can be denoted as $\tilde{A}=\left(a_{1}, a_{2}, a_{3}\right)$ where $a_{2}$ is the central value $\left(\mu_{\tilde{a}}(x)=1\right), a_{1}$ is the left spread and $a_{3}$ is the right spread. Linguistic terms, fuzzy numbers and schema of triangular fuzzy numbers have been presented in Table 1.

Table 1. Linguistic terms, fuzzy numbers and schema of triangular fuzzy numbers

\begin{tabular}{l|c|c}
\hline \multicolumn{1}{c|}{ Linguistic terms } & Triangular Fuzzy Number & Triangular Fuzzy Number \\
\hline Very High (VH) & $(7.5,10,10)$ & \\
\hline High (H) & $(5,7.5,10)$ & \\
\hline Medium (M) & $(2.5,5,7.5)$ & \\
\cline { 1 - 2 } Low (L) & $(0,2.5,5)$ & \\
\hline Very Low (VL) & $(0,0,2.5)$ & \\
\hline
\end{tabular}




\subsubsection{Defuzzification of RELC}

RELC should be transferred to the crisp number for calculating in later steps. Defuzzification operators are used for this purpose. Conceptually, the main duty of difuzzification operators is to define a point, which is a best representative of its own fuzzy sets. There are several defuzzification approaches (e.g. Centroid Index, Middle of Maxima, Largest of Maxima, Smallest of Maxima). Because most previous researchers have applied the centroid index (CI), the centroid index is also used in this paper. In this approach, the centroid of a fuzzy number is representative of its characteristics. CI can be described by two numbers regarding the $\mathrm{X}$ and $\mathrm{Y}$ axis. Some researchers have a contribution for using one number in $\mathrm{X}$ axis, e.g. Yager (1979) and some of them have used two numbers, e.g. Murakami et al. (1983).

Because of the simplicity of working with one number, this paper elects Yager's approach. The CI of $x$ value with the area $A(x)$ can be expressed as:

$$
C I=\frac{\sum_{x_{\min }}^{x_{\max }} x A(x)}{\sum_{x_{\min }} A(x)} .
$$

\subsection{Evaluation of existing project portfolio}

In this step, the existing project portfolio of a company should be evaluated. The concept of previous steps should be applied for determining the condition of the existing project portfolio with regard to the risk.

The main assumption of this model is that the existing projects constituted the company portfolio are not dependent; therefore, the risk number of company portfolio can be calculated by sum of each project risk number. For considering the importance of each project, the risk number of each project would be affected by its weight driven by the financial value of the project in the company portfolio.

The output of this step is so useful for managers, because they can understand where their company stands regarding the risk factor. They can compromise the risk level of the existing project portfolio and the RELC. According to this comparison, the strategy plan would be taken into account by one of these plans expressed in Table 2 .

Table 2. Strategy plans

\begin{tabular}{l|l}
\hline $\begin{array}{c}\text { Difference between } \\
\text { RELC and the risk of } \\
\text { existing portfolio }\end{array}$ & \multicolumn{1}{|c}{ Strategy } \\
\hline ERLC is lower & $\begin{array}{l}\text { Selecting projects which their risk } \\
\text { is lower than ERLC and also they } \\
\text { should be had considerable profits }\end{array}$ \\
\hline Minor differences & $\begin{array}{l}\text { Selecting projects which their risk } \\
\text { is equal to ERLC }\end{array}$ \\
\hline ERLC is higher & $\begin{array}{l}\text { Selecting projects which their risk } \\
\text { is higher than ERLC and also they } \\
\text { should be had considerable profits }\end{array}$ \\
\hline
\end{tabular}

In the next step, candidate projects will be evaluated and regarding to the expressed strategies, decision makers can choose an appropriate project.

\subsection{Evaluation of alternatives}

The process of evaluating alternatives has the same approach, which is applied for evaluating the existing project portfolio. Each alternative can be assessed by the criteria and FSAW described in the previous steps. The output of this phase is the ranking of alternatives with regard to their risk number.

\subsection{Developing zero-one linear goal programming (ZOLGP)}

Several useful tools exist for solving portfolio problems, but multi-objective decision-making approaches, which are one of the useful branches of MCDM methods, are more capable than others are in satisfying problems with various goals, therefore in this paper, linear goal programming is used. Because of the nature of selection problems, the authors decided to use zero-one linear goal programming. Generally, this paper applied zero-one goal programming because:

- ZOLGP is one of the best approaches for modeling problems with various and opposite goals;

- Developing the model is simple and understandable;

- Decision makers can prioritize goals;

- There is a harmony between model assumptions and real world problems.

Some general variables:

$X_{i}$ : Decision variables;

$X_{i j}=1$ if project $i$ is in the portfolio and start in pe$\operatorname{riod} j$, else $X_{i j}=0$;

$\mathrm{N}$ : Total number of projects being proposed;

$\mathrm{T}$ : Various periods in the strategic planning;

$d_{1}^{-}$: Negative deviation;

$d_{1}^{+}$: Positive deviation.

In this paper, goals are defined as follows:

1. Minimizing the difference between the project portfolio risk and RELC: if the risk of each project in the $j^{\text {th }}$ period of the project is presented by $r_{i}$, this goal would be defined as Eq. (11):

$$
\sum_{i=1}^{N} \sum_{j=1}^{T} r_{i} X_{i j}+d_{1}^{-}-d_{1}^{+}=E R L C .
$$

2. Regarding the simplicity of proposed model and releasing from dynamic computations, the main assumption of model in this step is the static condition. Authors assume when decision makers decide to select a project the RELC is constant. After adding new project in the organization portfolio, the new RELC should be determined and new selection can be done by this way.

3. Maximizing the benefit of project portfolio: if the benefit of the $i^{\text {th }}$ project presented by $b_{i}$ and 
the expected benefit of the portfolio is shown with $B$ this goal can be defined as Eq. (12):

$$
\sum_{i=1}^{N} \sum_{j=1}^{T} b_{i} X_{i j}+d_{2}^{-}-d_{2}^{+}=B
$$

4. Qualitative goals: if a company has some qualitative goals such as $Q$ this goal can be defined as Eq. (13). In this equation $q_{i}$ is the weight of the $i^{\text {th }}$ project in the evaluation process with regard to the qualitative goal:

$$
\sum_{i=1}^{N} \sum_{j=1}^{T} q_{i} X_{i j}+d_{3}^{-}-d_{3}^{+}=Q
$$

Also, constraints would be defined as follows:

1. Resource constraints: a company can model its limitation in supplying various resources such as financial, human, and equipment resources. If the project planning is divided into $\mathrm{T}$ period and the total resource in period $k$ is presented by $A F_{k}$ and the needed resource for the $i^{\text {th }}$ project is presented by $C_{(i, k+1-j)}$, this constraint can be formulated as Eq. (14):

$$
\sum_{i=1}^{N} \sum_{j=1}^{T} C_{(i, k+1-j)} X_{i j} \leq A F_{k}, \quad \text { For } \quad k=1, \ldots, T .
$$

2. Starting each project in one time: this constraint guarantees that each project, if selected, can start at once. Eq. (15) presents this limitation:

$$
\sum_{j=1}^{T} X_{i j} \leq 1, \quad \text { for } \quad i=1, \ldots, N .
$$

3. The constraint for completion of projects: Eq. (16) shows that the $i^{\text {th }}$ project for which duration is expressed by $D_{i}$ should be finished in the project portfolio planning:

$$
\sum_{j=1}^{T} j X_{i j}+D_{i} \leq T+1, \quad \text { for } i=1, \ldots, N .
$$

If a company needs to satisfy other goals and constraints, they can also be added. In general, the complete and detailed steps of the proposed model can be reviewed in Fig. 1.

\section{Illustrative example}

In order to better understand this framework, authors prepare an example in a real situation. In this section, a set of proposed projects is offered to the management department of a company and they should select a project or projects, which are suitable for their present project portfolio.

Because the object of this paper is to present a model for contractor companies, the candidates should be selected among contractors, and the company, which can pass the authors requirements, is selected among 172 contractor companies. This company is active in various fields and was established in 1975. The main field of this company is road and dam construction but it has some useful experience in other fields. This company is directly working with 65 engineers and more than 700 people in various projects.

The results of implementing the proposed model in this company are as follows:

a) In the first step, risk criteria should be determined. In this section, authors used an unofficial investigation conducted in the university. This research has surveyed the risk criteria and their weights among contractor companies. Since the authors intend to simulate the condition of this investigation to the real situation, risk criteria were offered to decision makers in the company in order to get their idea about them. After a session with decision makers, risk criteria and their categorization were modified as shown in Table 3 .

With respect to the approaches stated in step "a", weights of criteria were calculated by the participation of the principal personnel of the company as shown in Fig. 2.

b) For determining the RELC, the main people who make fundamental decisions and establish the strategy of a company are recognized. After studying the organization chart of a company, three persons inclusive of managing director, chairman of the board and technical manager were identified; therefore, the authors asked them about the risk level of each criterion that they can endure. Finally, based on the explained procedure for determining the RELC and by using FSAW the final fuzzy number resulted from their opinions is presented in Fig. 3. The crisp number of their RELC after the defuzzification process is 0.4346 from 1 .

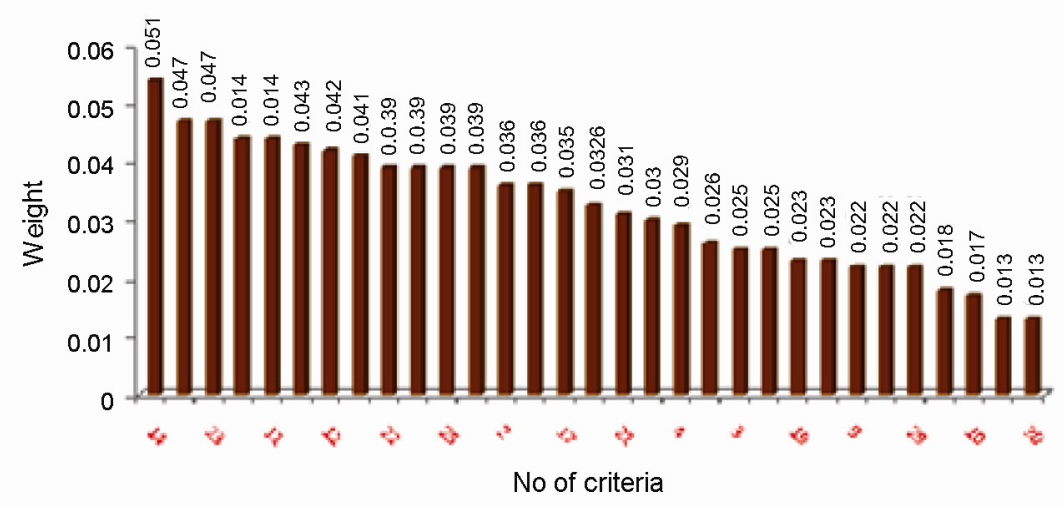

Fig. 1. The proposed model chart 
Table 3. Categorization and risk criteria

\begin{tabular}{|c|c|}
\hline Risk Criteria & No \\
\hline \multicolumn{2}{|l|}{ a) Financial and Economical Risk } \\
\hline a-1) interest rate & 1 \\
\hline a-2) inflation rate & 2 \\
\hline a-3) variation of petroleum price & 3 \\
\hline a-4) dependency to special moneylenders & 4 \\
\hline \multicolumn{2}{|l|}{ b) Industry } \\
\hline b-1) variation in government policies & 5 \\
\hline b-2) variation in production rate of principal materials & 6 \\
\hline b-3) international limitation & 7 \\
\hline b-4) variation in tariff & 8 \\
\hline b-5) permission licence & 9 \\
\hline b-6) environmental rules & 10 \\
\hline \multicolumn{2}{|l|}{ c) Contract } \\
\hline c-1) type of contract & 11 \\
\hline c-2) type of payment & 12 \\
\hline c-3) low credibility of employer & 13 \\
\hline c-4) low financial ability of employer & 14 \\
\hline c-5) unfamiliarity of consultant to technical work & 15 \\
\hline c-6) lack of cooperation history with consultant & 16 \\
\hline c-7) ambiguity in contract documentations & 17 \\
\hline \multicolumn{2}{|l|}{ d) Company } \\
\hline d-1) improper strategy in selection of region for work & 18 \\
\hline d-2) improper strategy in doing especial type of projects & 19 \\
\hline $\begin{array}{l}\text { d-3) lack of enough experience of project management } \\
\text { team }\end{array}$ & 20 \\
\hline $\begin{array}{l}\text { d-4) weak contractor relationship with employer organi- } \\
\text { zations }\end{array}$ & 21 \\
\hline d-5) lack of expert mangers & 22 \\
\hline \multicolumn{2}{|l|}{ e) Resource } \\
\hline e-1) lack of expert human resource & 23 \\
\hline e-2) lack of professional sub-contractors & 24 \\
\hline e-3) shortage of equipment and machines & 25 \\
\hline e-4) difficulty in supplying materials & 26 \\
\hline \multicolumn{2}{|l|}{ f) Project risk } \\
\hline f-1) design complexity & 27 \\
\hline f-2) execution complexity & 28 \\
\hline f-3) geographical and weather condition of project & 29 \\
\hline f-4) force majors & 30 \\
\hline f-5) unpredictable changes & 31 \\
\hline
\end{tabular}

c) Evaluation of existing projects is the next step. This step was done by the procedure explained in section "d". Table 4 presents general specifications and the risk of projects.

d) Evaluation of the proposed projects was done after specifying that the project has a positive potential for bidding. Specification and analysis of these projects is presented in Table 5.

e) Based on the existing project's planning and assumed planning of proposed projects, the expected cost and benefit table can be calculated. Tables 6 and 7 present that information. In those tables project number 1 to 3 are the existing projects and the others are proposed projects.

f) The final step in model implementation is to apply ZOLGP for the selection or ranking of proposed projects. In this section, LINDO software version 6.1 was applied. The problem was solved in a few minutes and the final answer is shown in figure (4). In this case, according to the decision maker, weights of all goals are equal.

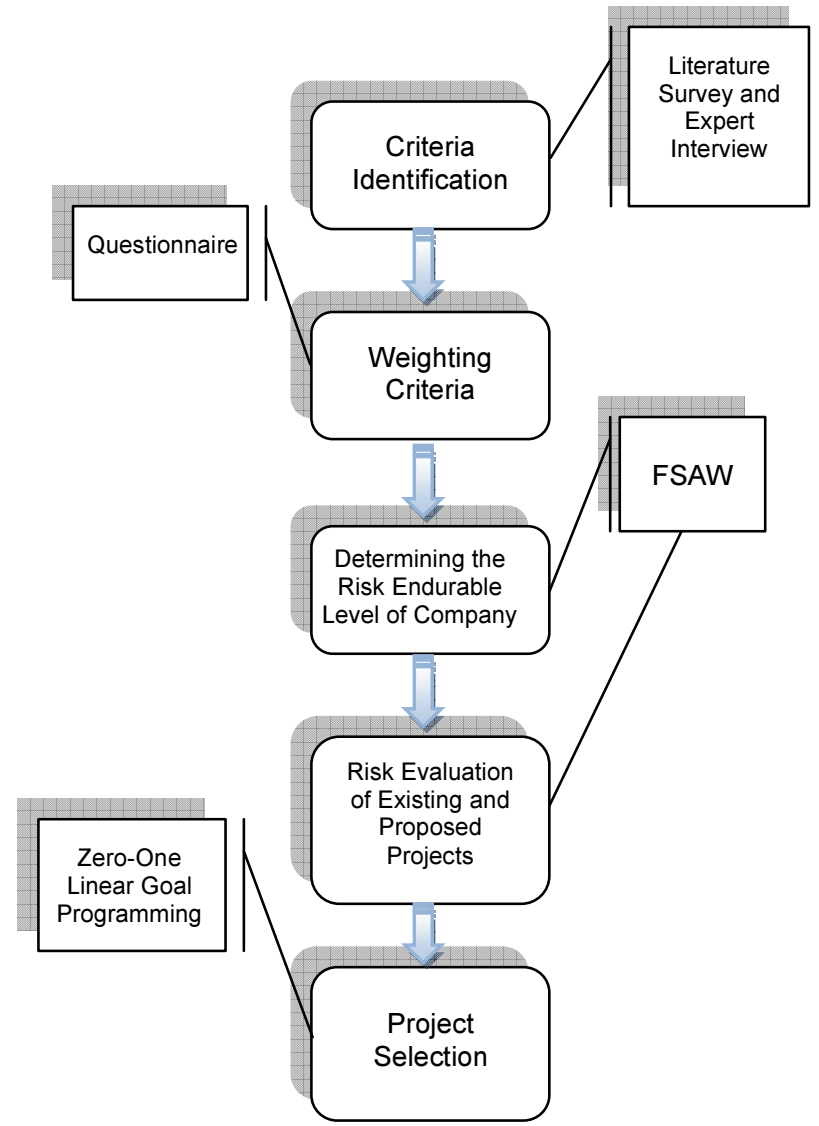

Fig. 2. The descending Pareto chart of criteria weight

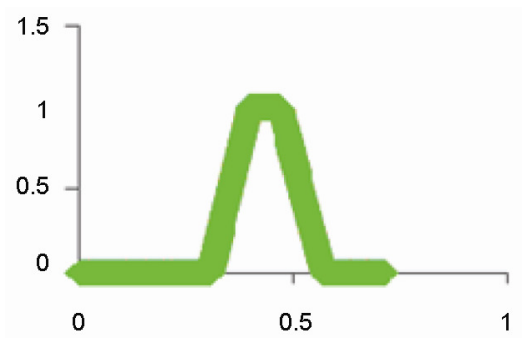

Fig. 3. The final fuzzy number of RELC

Regarding the concept of bid / no-bid and selection problems, choosing projects and starting them in the next periods is impossible so the earliest selection (first period) based on obtained schedule is the best solution of problem, so in this example, project No 5 is the best choice.

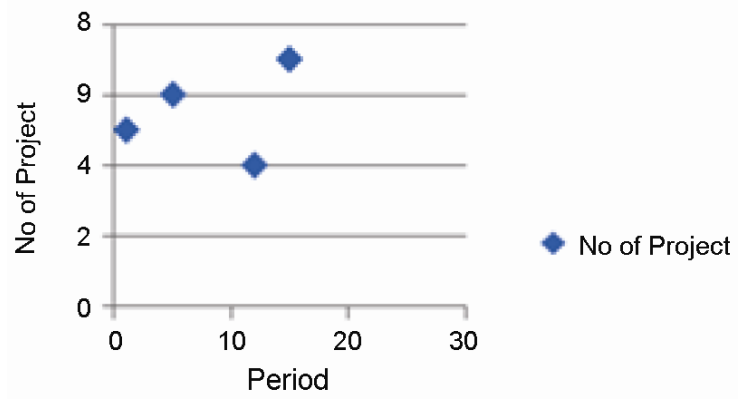

Fig. 4. Scheduling of portfolio 
Table 4. Evaluation of existing project

\begin{tabular}{|c|c|c|c|c|c|c|c|c|c|c|}
\hline No & Description & 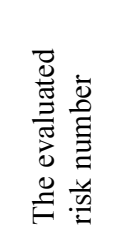 & 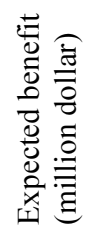 & 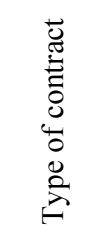 & 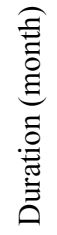 & 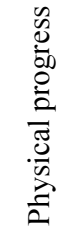 & 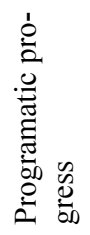 & 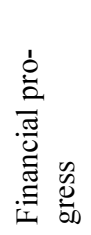 & 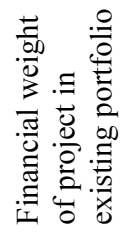 & 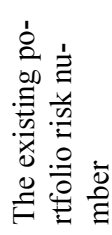 \\
\hline 1 & $\begin{array}{l}\text { Asaluyeh-Parsian highway } \\
\text { construction }\end{array}$ & 0.37105 & 10.4 & $\mathrm{EPC}^{*}$ & 34 & $80 \%$ & $91 \%$ & $77 \%$ & $54.7 \%$ & \multirow{3}{*}{0.4063} \\
\hline 2 & $\begin{array}{l}\text { Homa infrastructure construc- } \\
\text { tion }\end{array}$ & 0.36078 & 1.8 & $\mathrm{DBB}^{* *}$ & 12 & $18 \%$ & $22 \%$ & $11 \%$ & $9.50 \%$ & \\
\hline 3 & Ardabil rail way construction & 0.47236 & 5.1 & EPC & 36 & $34 \%$ & $52 \%$ & $13 \%$ & $35.80 \%$ & \\
\hline
\end{tabular}

Table 5. Specification and evaluated risk number of proposed projects

\begin{tabular}{c|l|c|c|c|c|c}
\hline No & \multicolumn{1}{|c|}{ Description } & Place & $\begin{array}{c}\text { Contract value } \\
\text { (million dollar) }\end{array}$ & $\begin{array}{c}\text { Type of } \\
\text { contract }\end{array}$ & $\begin{array}{c}\text { Duration } \\
\text { (month) }\end{array}$ & $\begin{array}{c}\text { The evaluated } \\
\text { risk number }\end{array}$ \\
\hline 1 & Rail way construction & Iran & 17.2 & EPC & 18 & 0.3874 \\
\hline 2 & Piping operation & Kazakhstan & 15.2 & EPC & 12 & 0.3974 \\
\hline 3 & Road construction & Iran & 20 & DBB & 20 & 0.3871 \\
\hline 4 & Dam construction & Iran & 68.1 & DBB & 36 & 0.4677 \\
\hline
\end{tabular}

Table 6. Execution cost distribution of projects

\begin{tabular}{|c|c|c|c|c|c|c|c|c|}
\hline \multirow{2}{*}{ Period } & \multirow{2}{*}{ Month } & \multicolumn{7}{|c|}{ Execution cost (hundred dollars) } \\
\hline & & Proj. No. 1 & Proj. No. 2 & Proj. No. 3 & Proj. No. 4 & Proj. No. 5 & Proj. No. 6 & Proj. No. 7 \\
\hline \multirow{6}{*}{1} & 1 & 51843.4 & 5205.5 & 2776.3 & 1532.1 & 2096.7 & 1761.9 & 4258.9 \\
\hline & 2 & 42799.5 & 10116.8 & 8640.2 & 7452.3 & 10198.5 & 8570.2 & 13254.1 \\
\hline & 3 & 40202.6 & 11334.3 & 11388.4 & 9822.7 & 13442.3 & 11296.1 & 17469.8 \\
\hline & 4 & 25277.9 & 9935.6 & 13837.9 & 11935.4 & 16333.5 & 13525.7 & 21227.3 \\
\hline & 5 & 6282.7 & 10279.0 & 11605.7 & 10010.1 & 13698.8 & 11511.6 & 17803.1 \\
\hline & 6 & - & 10352.4 & 11905.7 & 10268.8 & 14052.9 & 11609.2 & 18263.3 \\
\hline \multirow{6}{*}{2} & 7 & - & 8546.4 & 11528.8 & 9598.8 & 13135.9 & 11038.6 & 17685.2 \\
\hline & 8 & - & 8027.9 & 11445.9 & 9872.2 & 13510.2 & 11353.1 & 17558.0 \\
\hline & 9 & - & 5047.6 & 12636.7 & 9174.3 & 12555.1 & 10350.5 & 19384.8 \\
\hline & 10 & - & 1254.6 & 14594.4 & 6032.8 & 8255.9 & 6937.7 & 22387.9 \\
\hline & 11 & - & - & 15594.3 & 11725.3 & 16046.0 & 13484.0 & 23921.6 \\
\hline & 12 & - & - & 17230.1 & 13136.2 & 17974.2 & 15006.6 & 26431.0 \\
\hline \multirow{6}{*}{3} & 13 & - & - & 19750.6 & 11515.1 & 151300.0 & 13242.3 & 30297.4 \\
\hline & 14 & - & - & 17811.6 & 11912.7 & - & 13697.7 & 27723.0 \\
\hline & 15 & - & - & 16910.7 & 11998.2 & - & 13797.9 & 25944.0 \\
\hline & 16 & - & - & 14483.7 & 9904.9 & - & 11360.6 & 22218.0 \\
\hline & 17 & - & - & 13786.6 & 9303.6 & - & 10699.2 & 21118.7 \\
\hline & 18 & - & - & 12982.8 & 5850.3 & - & 6727.8 & 19915.7 \\
\hline \multirow{6}{*}{4} & 19 & - & - & 11897.0 & 1454.2 & - & 1672.3 & 18250.0 \\
\hline & 20 & - & - & 10998.9 & - & - & 1294.1 & 16872.3 \\
\hline & 21 & - & - & 10512.6 & - & - & 1063.0 & 16128.3 \\
\hline & 22 & - & - & 9998.7 & - & - & - & 15338.0 \\
\hline & 23 & - & - & 7891.2 & - & - & - & 12105.2 \\
\hline & 24 & - & - & 5591.2 & - & - & - & 8577.9 \\
\hline
\end{tabular}


Table 7. Expected benefit distribution of projects

\begin{tabular}{|c|c|c|c|c|c|c|c|c|}
\hline \multirow{2}{*}{ Period } & \multirow{2}{*}{ Month } & \multicolumn{7}{|c|}{ Expected benefit (hundred dollars) } \\
\hline & & Proj. No.1 & Proj. No.2 & Proj. No.3 & Proj. No.4 & Proj. No.5 & Proj. No.6 & Proj. No.7 \\
\hline \multirow{6}{*}{1} & 1 & 6968.7 & 1041.1 & 416.4 & 275.8 & 461.3 & 308.3 & 638.8 \\
\hline & 2 & 4759.9 & 2023.4 & 1296.0 & 1341.4 & 2243.7 & 1499.8 & 1988.1 \\
\hline & 3 & 2040.5 & 2266.9 & 1708.3 & 1768.1 & 2957.3 & 1976.8 & 2620.5 \\
\hline & 4 & 1795.6 & 1987.1 & 2075.7 & 2148.4 & 3593.4 & 2367.0 & 3184.1 \\
\hline & 5 & 1576.5 & 2055.8 & 1740.9 & 1801.8 & 3013.7 & 2014.5 & 2670.5 \\
\hline & 6 & 13180.8 & 2070.5 & 1785.9 & 1848.4 & 3091.6 & 2031.6 & 2739.5 \\
\hline \multirow{6}{*}{2} & 7 & - & 1709.3 & 1729.3 & 1727.8 & 2889.9 & 1931.8 & 2652.8 \\
\hline & 8 & - & 1605.6 & 1716.9 & 1777.0 & 2972.2 & 1986.8 & 2633.7 \\
\hline & 9 & - & 1009.5 & 1895.5 & 1651.4 & 2762.1 & 1811.3 & 2907.7 \\
\hline & 10 & - & 250.9 & 2189.2 & 1085.9 & 1816.3 & 1214.1 & 3358.2 \\
\hline & 11 & - & - & 2339.1 & 2110.5 & 3530.1 & 2359.7 & 3588.2 \\
\hline & 12 & - & - & 2584.5 & 2364.5 & 3954.3 & 2626.2 & 3964.6 \\
\hline \multirow{6}{*}{3} & 13 & - & - & 2962.6 & 2072.7 & 33286.0 & 2317.4 & 4544.6 \\
\hline & 14 & - & - & 2671.7 & 2144.3 & - & 2397.1 & 4158.5 \\
\hline & 15 & - & - & 2536.6 & 2159.7 & - & 2414.6 & 3891.6 \\
\hline & 16 & - & - & 2172.6 & 1782.9 & - & 1988.1 & 3332.7 \\
\hline & 17 & - & - & 2068.0 & 1674.7 & - & 1872.4 & 3167.8 \\
\hline & 18 & - & - & 1947.4 & 1053.1 & - & 1177.4 & 2987.3 \\
\hline \multirow{6}{*}{4} & 19 & - & - & 1784.5 & 261.8 & - & 292.7 & 2737.5 \\
\hline & 20 & - & - & 1649.8 & - & - & 226.5 & 2530.8 \\
\hline & 21 & - & - & 1576.9 & - & - & 186.0 & 2419.2 \\
\hline & 22 & - & - & 1499.8 & - & - & - & 2300.7 \\
\hline & 23 & - & - & 1183.7 & - & - & - & 1815.8 \\
\hline & 24 & - & - & 838.7 & - & - & - & 1286.7 \\
\hline
\end{tabular}

Table 8. The results on altering weight of goals

\begin{tabular}{l|c|c|c}
\hline \multirow{2}{*}{ Scenario } & \multicolumn{2}{|c|}{ Criteria } & \multirow{2}{*}{ Answer } \\
\cline { 2 - 3 } & Benefit & Risk & $\mathrm{X} 11, \mathrm{X} 21, \mathrm{X} 31, \mathrm{X} 51, \mathrm{X} 76$ \\
\hline \multirow{3}{*}{ Increasing benefit } & 2 & 1 & $\mathrm{X} 11, \mathrm{X} 21, \mathrm{X} 31, \mathrm{X} 55, \mathrm{X} 46, \mathrm{X} 76$ \\
\cline { 2 - 4 } & 5 & 1 & $\mathrm{X} 11, \mathrm{X} 21, \mathrm{X} 31, \mathrm{X} 54, \mathrm{X} 46, \mathrm{X} 76$ \\
\cline { 2 - 4 } Increasing risk & 8 & 1 & $\mathrm{X} 11, \mathrm{X} 21, \mathrm{X} 31, \mathrm{X} 74$ \\
\cline { 2 - 4 } & 1 & 5 & $\mathrm{X} 11, \mathrm{X} 21, \mathrm{X} 31, \mathrm{X} 34, \mathrm{X} 46, \mathrm{X} 76$ \\
\cline { 2 - 4 } & 1 & 8 & $\mathrm{X} 11, \mathrm{X} 21, \mathrm{X} 31, \mathrm{X} 51, \mathrm{X} 46, \mathrm{X} 76$ \\
\hline Just benefit & 1 & 0 & $\mathrm{X} 11, \mathrm{X} 21, \mathrm{X} 31, \mathrm{X} 42, \mathrm{X} 66, \mathrm{X} 66, \mathrm{X} 76$ \\
\hline Just risk & 0 & 1 &
\end{tabular}

It should be noticed that project portfolio selection is the dynamic problem so authors suggest that decision makers add one project to the portfolio and for next choice, determining new RELC is necessary. In most situations, decision makers can reach to the best solution with a few iterations.

\section{Discussion}

For enhancing the comprehension and searching the applicability of model, a sensitivity analysis is developed in this section. There are three main goals in this model and in the example just two goals, entitled risk and benefit were used. With changing the weight of each goal several modes can be distinguished. Table 8 demonstrates three main scenarios and related results.

In the first scenario, the weight of benefit increased to the various degrees while the weight of risk has stayed unchanged. Considering the results obtained in each level, variety and scheduling of portfolio have completely changed. With increasing the weight of benefit, selected portfolio tended to arrange projects with high-expected incomes and as a result increasing in the risk level of portfolio occurred in this example.

In the next plan, the weight of risk enhanced with no alteration in the weight of benefit. The results demonstrated that selected portfolio is disposed toward balancing 
the risk of portfolio with RELC. Considering to the different conditions of proposed projects, the behavior of selected portfolio regarding benefit is heterogeneous.

In the third scenario, individual goal was studied. The combination of portfolio was completely altered and the number of selected projects increased. When just one goal is considered, decision makers should be careful about the effect of eliminated goals on selection process. For example, when the selection is done based on benefit goal, enhancing the risk of portfolio is noticeable.

The results of sensitivity analysis can be taken into account as below:

1. Preparing these analyses and doing sensitivity analysis for decision makers can be useful. It prepares a wide range of alternatives that decision makers can select their own desired choice;

2. Sensitivity analysis can demonstrate the applicability and reliability of model in various situations. Sensitivity of model to changing its parameters is observable so it can be used in different conditions.

\section{Conclusions}

This paper offers a new framework in bid/no-bid strategy by implementing the new project portfolio selection methodology based on the risk factor. The main innovation of this paper is to optimize the risk of the organization portfolio. Approximately, all of previous authors considered the risk as a negative criterion and they did not consider the direct interaction between risk and benefit or income. This paper attempts to solve this problem and proposes a model for getting the optimized point in risk and income interaction (portfolio theory) based on the present status of the company. This object was satisfied by defining RELC that prepares a tool for the company to determine the rate of risk, which it can endure. After this process, the model selects projects with minimum deviation from RELC. Using a fuzzy set theory leading to this model will be user friendly because of its capability of working with expert's linguistic terms. This model is also very flexible for being implemented in all companies because of its adjustment to the present condition. The results of implementing the model could satisfy experts very much. It seems the concept explained in this paper can be useful for selection of the best strategy in bid/no-bid decision-making.

As the authors discussed the restraints and their assumption, further research can be defined for eliminating expressed assumptions. The most important task that can be carried out by researchers is to propose a model by considering an interdependency of projects on the portfolio. The second task is to define some other fields, not considering the risk factor or by combining various objects for the selection of the best project.

\section{References}

Ahmed, S. M.; Azhar, S.; Ahmad, I. 2002. Evaluation of Florida General Contractors' risk management practices, Revista Ingeniera de la Construction [Journal of Construction Engineering] 17(1): 4-11.
An, M.; Baker, C. J.; Zeng, J. 2005. A fuzzy-logic-based approach to qualitative risk modeling in the construction process, World Journal of Engineering 2(1): 1-12.

Archer, N. P.; Ghasemzadeh, F. 1998. A decision support system for project portfolio selection, International Journal of Technology Management 16(1/2/3): 105-114.

Baas, S. M.; Kwakernaak, H. 1977. Rating and ranking of multiple aspect alternative using fuzzy sets, Automatica 13(1): 47-58. http://dx.doi.org/10.1016/0005-1098(77)90008-5

Baker, D.; Ponniah, D.; Smith, S. 1998. Techniques for the analysis of risks in major projects, Journal of the Operational Research Society 49(6): 567-572. http://dx.doi.org/10.1057/palgrave.jors.2600548

Baloi, D.; Price, A. D. F. 2003. Modelling global risk factors affecting construction cost performance, International Journal of Project Management 21(4): 261-269. http://dx.doi.org/10.1016/S0263-7863(02)00017-0

Bector, C. R.; Appadoo, S. S.; Chandra, S. 2002. Weighted factors scoring model under fuzzy data, in Proc. of the $30^{\text {th }}$ Annual Conference of Administrative Sciences Association of Canada, 27 May, 2002, Winnipeg, Manitoba, 95-105.

Bonissone, P. P. 1982. A fuzzy set based linguistic approach: theory and applications, in M. M. Gupta, E. Sanchez (Eds.). Approximate Reasoning in Decision Analysis. USA, North-Holland, Canada: Elsevier Science Pub. Co., 329-339.

Carlsson, C.; Fullér, R.; Heikkilä, M.; Majlender, P. 2007. A fuzzy approach to $\mathrm{R} \& \mathrm{D}$ project portfolio selection, International Journal of Approximate Reasoning 44(2): 93105. http://dx.doi.org/10.1016/j.ijar.2006.07.003

Carr, V.; Tah, J. H. M. 2001. A fuzzy approach to construction project risk assessment and analysis: construction project risk management system, Advances in Engineering Software 32(10): 847-857. http://dx.doi.org/10.1016/S0965-9978(01)00036-9

Cheng, E. W. L.; Heng, L. 2005. Analytic Network Process Applied to Project Selection, Journal of Construction Engineering and Management ASCE 131(4): 459-466. http://dx.doi.org/10.1061/(ASCE)0733-9364(2005)131: 4(459)

Cheng, Y. M.; McInnis, B. 1980. An algorithm for multiple attribute, multiple alternative decision problem based on fuzzy sets with application to medical diagnosis, IEEE Transactions on System, Man and Cybernetics 10(10): 645-650. http://dx.doi.org/10.1109/TSMC.1980.4308371

Dubois, D.; Prade, H. 1982. The use of fuzzy numbers in decision analysis, in M. M. Gupta, E. Sanchez (Eds.). Fuzzy Information and Decision Processes. USA, NorthHolland, Canada: Elsevier Science Pub. Co., 309-321.

Han, S. H. 1999. Risk-based Go/No-Go decision making model for international construction projects: The Cross-impact analysis approach. $\mathrm{PhD}$ thesis. Boulder, Colorado: University of Colorado at Boulder.

Han, S. H.; Diekmann, J. E.; Ock, J. H. 2005. Contractor's risk attitudes in the selection of international construction projects, Journal of Construction Engineering and Management ASCE 131(3): 283-292. http://dx.doi.org/10.1061/ (ASCE)0733-9364(2005)131: 3(283)

Hao, L.; Xie, Q. 2006. Application of TOPSIS in the bidding evaluation of manufacturing enterprises the algorithm of TOPSIS, in Proc. of the $5^{\text {th }}$ International Conference on eEngineering \& Digital Enterprise Technology (eENGDET2006), 16-18 August, 2006, Guiyang, China, 184-188. 
Huang, C.-C.; Chu, P.-Y.; Chiang, Y.-H. 2008. A fuzzy AHP application in government sponsored R\&D project selection, Omega 36(6): 1038-1052.

http://dx.doi.org/10.1016/j.omega.2006.05.003

Kahraman, C. 2008. Fuzzy multi-criteria decision making theory and applications with recent development. Volume 16 of Springer Optimization and Its Applications. Springer Science. $591 \mathrm{p}$.

Kangari, R.; Boyer, L. T. 1981. Project selection under risk, Journal of Construction Division ASCE 107(4): 597-608.

Kangari, R.; Riggs, L. S. 1988. Portfolio management in construction, Construction Management and Economics 6(2): 161-169. http://dx.doi.org/10.1080/01446198800000014

Lin, C.-T.; Chen, Y.-T. 2004. Bid/no-bid decision-making-a fuzzy linguistic approach, International Journal of Project Management 22(7): 585-593. http://dx.doi.org/10.1016/j.ijproman.2004.01.005

Liu, M.; Ling, Y. Y. 2005. Modeling a contractor's markup estimation, Journal of Construction Engineering and Management ASCE 131(4): 391-399. http://dx.doi.org/10. 1061/(ASCE)0733-9364(2005)131: 4(391)

Mahmoodzadeh, S.; Shahrabi, J.; Pariazar, M.; Zaeri, M. S. 2007. Project selection by using fuzzy AHP and TOPSIS technique, International Journal of Human and Social Sciences 2(7): 397-402.

Molenaar, K. R.; Songer, A. D. 1998. Model for public sector design-build project selection, Journal of Construction Engineering and Management ASCE 124(6): 467-479. http://dx.doi.org/10.1061/(ASCE)0733-9364(1998)124: 6(467)

Moselhi, O.; Deb, B. 1993. Project selection considering risk, Construction Management and Economics 11(1): 45-52. http://dx.doi.org/10.1080/01446199300000063

Mullich, J. 1998. Project portfolio management for the new millennium [online]. Information Week [cited 19 January, 2011]. Available from Internet: http//www.primavera.com.

Murakami, S.; Maeda, S.; Imamura, S. 1983. Fuzzy decision analysis on the development of centralized regional energy control system, in IFAC Symposium on Fuzzy Information. Knowledge Representation and Decision Analysis, 1983, 363-368.

Olsson, R. 2008. Risk management in a multi-project environment an approach to manage portfolio risks, International Journal of Quality \& Reliability Management 25(1): 6071. http://dx.doi.org/10.1108/02656710810843586

Oo, B.-L.; Drew, D. S.; Lo, H.-P. 2008. Heterogeneous approach to modeling contractors' decision-to-bid strategies, Journal of Construction Engineering and Management ASCE 134(10): 766-775. http://dx.doi.org/10.1061/ (ASCE)0733-9364(2008)134: 10(766)

Ravanshadnia, M.; Rajaie, H.; Abbasian, H. R. 2010. Hybrid fuzzy MADM project-selection model for diversified construction companies, Canadian Journal of Civil Engineering 37(8): 1082-1093.

http://dx.doi.org/10.1139/L10-048

Hamidreza ABBASIANJAHROMI. PhD Candidate in Construction Engineering and Management at Amirkabir University of Technology, Tehran, Iran. He is member of Iran Project Management Association. His research interests include decision-making problems in construction, application of fuzzy set theory in construction, project selection, risk management and contractor/subcontractor selection and assessment.

Hossein RAJAIE. Dr, Assistant Professor of Civil Engineering Faculty at Amirkabir University of Technology, Tehran, Iran. He is member of Concrete Research Center of Amirkabir University, academic member of Building and Housing Research Center, Tehran, Iran. His research interests are portfolio management, decision-making problems in construction, project selection, contractor selection, material Selection in construction industry. 